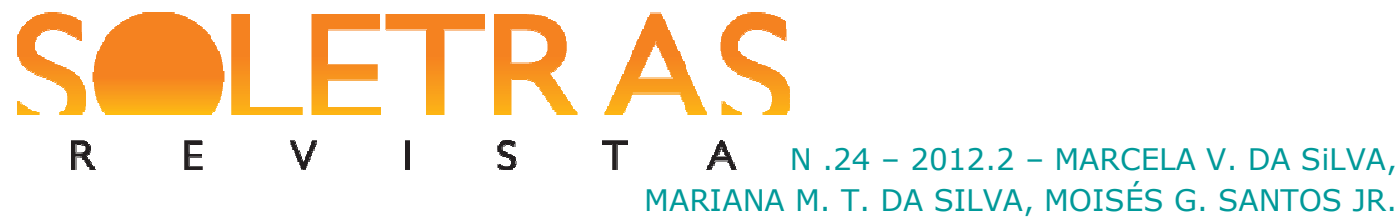

\title{
As vanguardas europeias na criação estética de Anita Malfatti e Cecília Meireles: um estudo interartes
}

\author{
Marcela Verônica da Silva ${ }^{1}$ \\ Mariana Matheus Pereira da Silva ${ }^{2}$ \\ Moisés Gonçalves dos Santos Junior ${ }^{3}$
}

Resumo: Na modernidade, as relações interartes intensificam-se, pois o que caracteriza os movimentos modernos são atividades, programas e manifestos partilhados por artistas de vários campos. Com o Modernismo e o advento das chamadas correntes vanguardistas, renovam-se as experiências poético-pictóricas. O presente artigo pretende discutir a interferência dos movimentos vanguardistas do início do século $\mathrm{XX}$ no processo de composição artística brasileira. Tais discussões serão pautadas nas obras da artista plástica Anita Malfatti e da poeta Cecília Meireles. Para tanto, o corpus selecionado é composto pelo quadro "A mulher de cabelos verdes" (1915-1916) e pelo poema "Desenhos do sonho", presente na obra Sonhos, publicada na coletânea Obra Completa (1994).

Palavras chave: Vanguardas. Anita Malfatti. Cecília Meireles.

\section{Introdução}

A pintura é poesia muda e a poesia é uma pintura falante.

(Plutarco, De gloria Atheniensium III)

No decorrer dos diferentes movimentos artísticos, a correspondência entre as artes foi praticada tanto por artistas quanto por filósofos. Percebe-se essa atitude em cingir as artes em estudo, tanto no aforismo constante na epígrafe acima, de autoria de Simónides de Ceos (V a. C.) recuperado por Plutarco, quanto na Arte Poética de Horácio (20 a. C.), que estabeleceu a máxima ut pictura poesis, interpretada como um princípio de similaridade entre pintura e

\footnotetext{
${ }^{1}$ Marcela Verônica da Silva é doutoranda em Literatura Brasileira pela Universidade Estadual Paulista Júlio de Mesquita Filho (2013). Participa dos grupos de pesquisa “A Escrita no Brasil Colonial e suas relações” (UNESPAssis) e "Literatura e História: Memória e Representação" (UENP-Jacarezinho). Atua como Professora Colaboradora na área de Literatura Brasileira na Universidade Estadual do Norte do Paraná. E-mail: maveronica83@yahoo.com.br.

${ }^{2}$ Mariana Matheus Pereira da Silva é graduada em Letras - Português/Literatura pela Universidade Estadual do Norte do Paraná, campus de Jacarezinho. Participa do Grupo de Pesquisa "Literatura e Ensino", na linha Literatura na escola: teorias e práticas. Foi bolsista de Iniciação Científica pela Fundação Araucária (2011/2012). E-mail: mari_mrn@hotmail.com.

${ }^{3}$ Moisés Gonçalves dos Santos Júnior é graduado em Letras - Português/Literatura pela Universidade Estadual do Norte do Paraná, campus Jacarezinho. Participa do Grupo de Pesquisa "Literatura e História: Memória e Representação”. Foi bolsista de Iniciação Científica pelo CNPq (2010/2011). moises_jr3@ hotmail.com.
} 


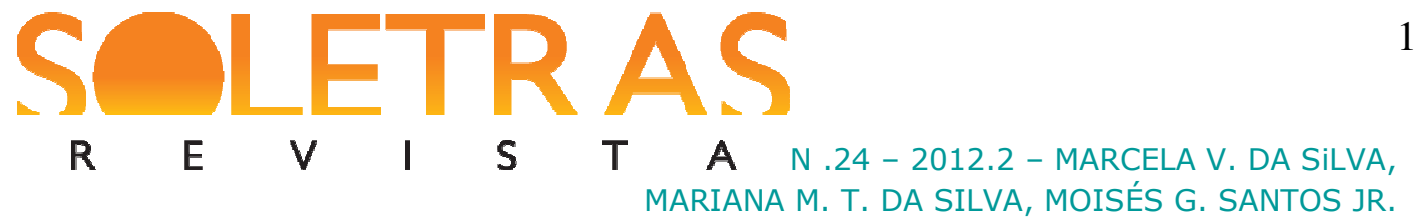

poesia. Para ambos os pensadores, a comparação se basearia no fato de pintura e poesia serem imitações da natureza.

A investigação acerca da relação entre as artes remonta, assim, à Antiguidade, na medida em que, les relations de l'art pictural et de la littérature sont aussi anciennes que les mondes $^{4}$ (DAVIGNON apud PEDROSO JÚNIOR, 2009, p. 105).

A citação de Simónides de Ceos, diferentemente da teoria de Horácio, tem a intenção de afirmar a comparação entre a poesia e a pintura de forma intencional, para tentar elevar a poesia ao status de tekhnê, pois, segundo Gali (1999, p. 162),

[...] sólo en el momento en que la poesía se convierte en una tekhnê puede compararse con, y distanciar-se de, otras disciplinas - pintura, escultura, arquitectura, tejido o bordado - tradicionalmente consideradas tekhnai, esto es, como actividades no inspiradas 5 .

Segundo Pedroso Júnior (2009):

O adágio de Simônides traz outras implicações para os estudos interartes, na medida em que pode ser complementado com outra afirmação do próprio poeta grego, para quem "la palabra es la imagen de las cosas" (GALÍ, 1999, p. 162).

Simónides de Céos, assim, prenunciava os preceitos estéticos das artes anunciando a intensa correspondência entre palavra e imagem.

No Brasil, a Semana de Arte Moderna de 1922 representou o estopim de uma série de tentativas de ruptura com a arte vigente até então. Contou com nomes como os de Graça Aranha, Manuel Bandeira, Mário de Andrade e Oswald de Andrade na literatura, Villa-Lobos na música, Victor Becheret na escultura e Anita Malfatti, Di Cavalcanti nas artes plásticas entre outros. Essa semana representou também o anseio de criar uma arte própria, "autenticamente" brasileira.

A semana foi, ao mesmo tempo, o ponto de encontro das várias tendências modernas que desde a primeira guerra se vinham firmando em São Paulo e no Rio e a plataforma que permitiu a consolidação de grupos, a publicação

\footnotetext{
4 “As relações entre artes visuais e literatura são tão antigas quanto os mundos” [Nossa tradução].

5 "Só no momento em que a poesia se torna um tekhnê, pode comparar-se com, e distanciar-se de, outras disciplinas - pintura, escultura, arquitetura, costura ou bordado - tradicionalmente considerado tekhnai, isto é, como atividades sem inspiração" [Nossa tradução].
} 


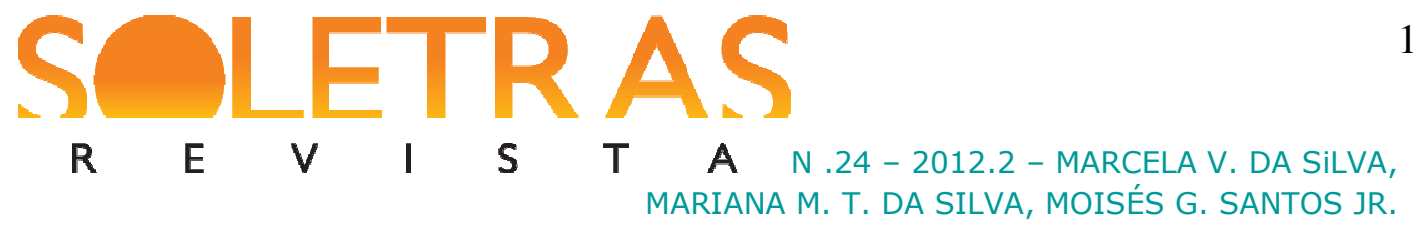

de livros, revistas e manifestos, numa palavra, o seu desdobrar-se em viva realidade cultural (BOSI, 1972, p. 383).

T. S. Eliot, em "Tradição e talento individual” (1989), trata da crítica literária e do conceito de originalidade e defende a ideia de que não existe purismo, uma vez que as artes dependem de uma tradição. O anseio pelo novo, que direcionava os interesses dos integrantes da Semana de Arte Moderna, desdobrou-se em retomadas das vanguardas europeias, ou seja, a arte brasileira inevitavelmente estava atrelada aos pressupostos estéticos europeus.

No Manifesto Antropofágico (1928), por exemplo, o espírito crítico e zombeteiro de Oswald de Andrade elaborou uma miscelânea das principais manifestações vanguardistas, todavia, valorizando e evidenciando aspectos da cultura nacional, em um poderoso e fértil processo de intertextos que, com a ressonância desta certidão-síntese, no Movimento Tropicalista - ou Tropicália -, da década de 60, congregou inúmeros diálogos entre literatura, música, artes plásticas, cinema etc.

As relações interartes, assim, permanecem ao longo dos tempos. Na modernidade, inclusive, elas se intensificam, pois o que caracteriza os movimentos modernos são atividades, programas e manifestos partilhados por artistas de vários campos. Com o Modernismo e o advento das correntes vanguardistas, renovam-se as experiências poético-pictóricas. A título de exemplo, podem ser citados os caligramas de Guilhaume Apollinaire e a poesia concretista brasileira dos irmãos $\operatorname{Campos}^{6}$, que buscam transformar a poesia em arte visual.

$\mathrm{O}$ presente artigo pretende, assim, discutir a interferência dos movimentos vanguardistas do início do século XX no processo de composição artística brasileira. Para tanto, o corpus selecionado é composto pelo quadro "A mulher de cabelos verdes" (19151916) e pelo poema "Desenhos do sonho", presentes na coletânea "Sonhos", publicada na obra Poesia Completa (1994).

\section{As experiências vanguardistas na pintura e na literatura: Anita Malfatti e Cecília Meireles}

O termo vanguarda, segundo Lúcia Helena (1993) é de origem militar, vem da língua francesa e refere-se a avant-garde, que significa "marchar na frente". Refere-se, deste modo, à parte de um exército situado à frente do corpo principal, à frente das tropas. No âmbito das artes, o termo adquire sentido semelhante, uma vez que, devido ao próprio contexto histórico,

\footnotetext{
${ }^{6}$ Augusto de Campos e Haroldo de Campos.
} 


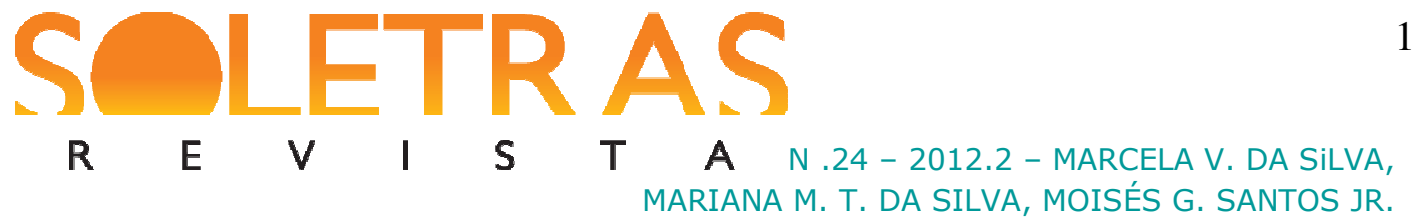

filosófico e cultural apresenta um caráter combativo. Os vanguardistas estavam dispostos a lutar agressivamente em prol da renovação e da transformação.

As vanguardas europeias do alvorecer do século XX constituem movimentos de revolta contra o tradicionalismo "raquítico" e as tendências do final do XIX, como o Decadentismo, o Simbolismo e o Penumbrismo. Surgem em torno da chamada Belle Époque e da I Guerra Mundial, tornando-se um dos mais inovadores Zeitgeist que regem o espírito da época e que influenciaram consubstancialmente toda a produção artística tida como moderna e contemporânea.

Segundo Teles (2000, p. 27), autores como Edgar Allan Poe, Walt Whitman, Charles Baudelaire, Lautrèmont, Arthur Rimbaud e Stéphane Mallarmè apontam na poesia ocidental os pontos de ruptura estética e temática que determinaram o advento de grupos de vanguarda na poesia europeia do início do século XX. Nesse momento, Paris vivia a euforia de sua Belle Èpoque e o pessimismo decadentista do fim do século.

As ideias filosóficas e sociológicas e o desenvolvimento científico e técnico da época colaboraram para a agitação espiritual e intelectual dos escritores e demais artistas, que se dividiam entre passado e futuro, o que motivava investigações em todos os campos da arte e transformava os primeiros anos do século $\mathrm{XX}$ no cenário das mais revolucionárias experiências de arte e de literatura, e foi por pertencer a este contexto que o nome vanguarda foi tão bem aceito.

Ainda de acordo com Teles (2000), entre os anos de 1848 a 1870, a metáfora estética sofreu um deslocamento. A arte de vanguarda, inicialmente, ficava restrita ao progresso social e se posicionava esteticamente à frente do seu tempo. Esse deslocamento relaciona-se com a autonomia da arte, evocada a respeito de Manet, que dizia que, se a arte de vanguarda merece essa denominação antes de 1848 , por seus temas, a arte de depois de 1870 a merecerá por suas formas.

No Brasil, como ressonância direta das estéticas vanguardistas europeias, Cecília Meireles cria uma produção poética congregando várias correntes que inauguram o pensamento moderno nas artes mundiais. Classificada pelos críticos como neossimbolista, neoexpressionista e até mesmo surrealista, Meireles consegue atingir uma expressividade poética universal ao trabalhar com símbolos, correspondências que sugerem estados da alma humana e questões psicológicas que envolvem sonhos, delírios, ilogismo, sensações que convergem para a expressão do mundo interior. 


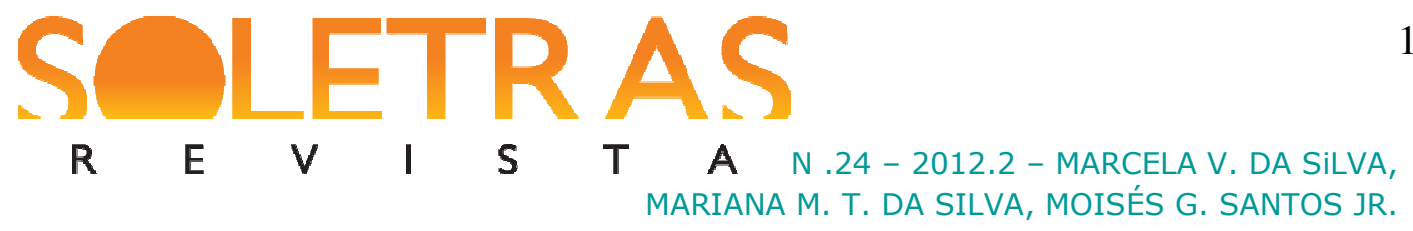

Segundo Bosi (2006, p. 461), a poeta "parte de certo distanciamento do real imediato e norteia os processos imagéticos para a sombra, o indefinido, quando não para o sentimento da ausência e do nada”.

Sua obra, segundo Ayala (1994, p. 12), é comparada a "um caprichoso desenho, que nos leva a revelação de um mundo que nos insere, e o qual muitas vezes perdemos”. Assim, os “desenhos da vida" feitos por Meireles mostram sua focalização em temas transcendentes que afirmam uma consciência visual capaz de transformar o cotidiano simples em quadros cheios de vitalidade.

Anita Malfatti, por sua vez, também busca realizar a desconstrução da realidade em sua obra, representa-a de acordo com a concepção de arte expressionista/cubista. Nesse ponto, sua produção dialoga com a poesia de Cecília Meireles, uma vez que, ligadas por um eixo comum, o da desconstrução, ambas as artes acabam por provocar no espectador/leitor a sensação de falta de sustentação lógica, traço recorrente em inúmeras manifestações vanguardistas, mas, sobretudo, nas estéticas expressionista e surrealista.

Em "Desenho do Sonho", de Cecília Meireles, a união de termos reais com termos abstratos e a escolha de um léxico simbólico favorece a "quebra" na estrutura tradicional. Já em Anita Malfatti, as cores são o elemento de maior destaque, pois essa ruptura com o real ocorre principalmente pela escolha inusitada, que, inclusive, qualifica os seres representados em sua pintura, diferindo-os de meros retratos, uma vez que, através da cor tem-se a ruptura com o lógico e a intensificação dos sentimentos, a exemplo do quadro "O homem amarelo" e "A mulher de cabelos verdes", cujos títulos provocaram no expectador da época questionamentos e estranhamento.

No poema "Desenhos do Sonho", os versos iniciais "Eu, mulher dormente, / na líquida noite / alargo a ramagem de meus cabelos verdes" (MEIRELES, 1994, p. 1264) demonstram um eu-lírico feminino envolto em uma atmosfera de sonho e devaneio, narrando suas experiências insólitas e vagas. A imagem que sobressai expressivamente são os cabelos verdes da mulher, cor que, numa realidade verossímil, seria impossível, mas que dentro das fronteiras do inconsciente, do ilógico, concretiza-se com perfeita naturalidade.

Mário de Andrade (1921) afirma que distinguia na obra de Anita Malfatti alguns “estados emocionais" a partir das cores "não naturalistas".

[...] dentro da impetuosidade de seu temperamento, dentro da máscula força com que lida as suas cores e risca os seus esboços, ou da trágica energia com 


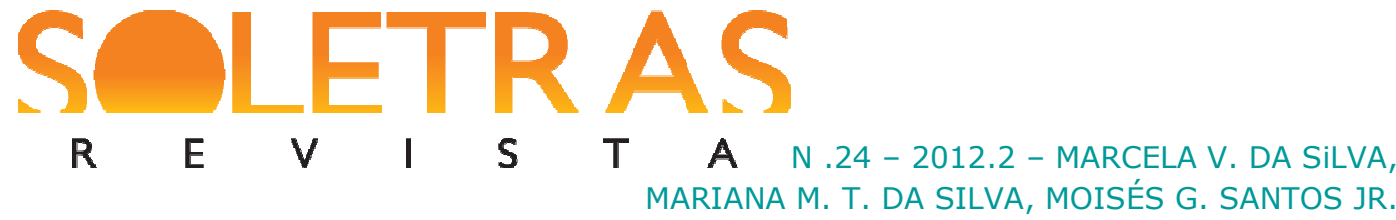

que escolhe seus assuntos, indelevelmente imprime aos seus trabalhos o delicioso que dá graça ou dá tristeza. Assim: A mulher de cabelos verdes, apesar da estranha fantasia é um poema de bondade e a figura fatídica do Homem Amarelo é feminilizada por uns olhos longínquos, cheios de nostalgia. Mas é principalmente nos retratos femininos que se encontrará a graça melindrosa do pincel de Anita Malfatti (ANDRADE apud BATISTA, 2006, p. 270, grifo nosso).

Batista (2006) traça a trajetória da artista, afirmando seu vínculo com certas questões do expressionismo alemão, sobretudo referentes a um suposto "tema expressionista", baseado na investigação ou intenção da artista em desenvolver temas centrados nos dramas humanos ou nas novas relações do homem com as questões do mundo moderno. No caso de Anita Malfatti, a artista chegou a interpretar um "drama humano" não só universal, mas derivado sua própria biografia.

Em um relato, a artista descreve um momento de infância:

Eu tinha 13 anos, e sofria porque não sabia que rumo tomar na vida. Nada ainda me revelara o fundo da minha sensibilidade [...]. Resolvi, então, me submeter a uma estranha experiência: sofrer a sensação absorvente da morte. Achava que uma forte emoção, que me aproximasse violentamente do perigo, me daria a decifração definitiva da minha personalidade. E veja o que fiz. Nossa casa ficava próxima da estação da Barra Funda. Um dia saí de casa, amarrei fortemente as minhas tranças de menina, deitei-me debaixo dos dormentes e esperei o trem passar por cima de mim. Foi uma coisa horrível, indescritível. O barulho ensurdecedor, a deslocação de ar, a temperatura asfixiante deram-me uma impressão de delírio e de loucura. E eu via cores, cores e cores riscando o espaço, cores que eu desejaria fixar para sempre na retina assombrada. Foi a revelação: voltei decidida a me dedicar à pintura. ${ }^{7}$

Suas vivências e seu contato com as artes vanguardistas formaram o esteio de sua pintura. A exposição realizada em São Paulo em 1917 representa, no Brasil, a cisão entre o tradicional e o moderno. No dia 20 de dezembro de 1917, Monteiro Lobato publica o artigo “Paranóia ou Mistificação?”. Nele, critica a arte de Anita Malfatti, episódio que culmina no início da estética modernista no Brasil:

Estas considerações são provocadas pela exposição da sra. Malfatti, onde se notam acentuadíssimas tendências para uma atitude estética forçada no sentido das extravagâncias de Picasso \& Cia. [...] Sejamos sinceros: futurismo, cubismo, impressionismo e tutti quanti não passam de outros

\footnotetext{
${ }^{7}$ Depoimento retirado do site http://quadroseretratos.wordpress.com/2012/06/11/a-pintora-de-22/. Acesso em 21 de setembro de 2012.
} 


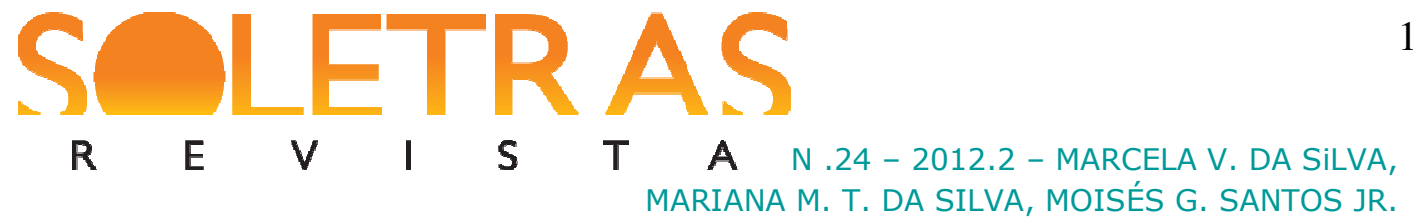

ramos da arte caricatural. É a extensão da caricatura a regiões onde não havia até agora penetrado. Caricatura da cor, caricatura da forma - mas caricatura que não visa, como a verdadeira, ressaltar uma idéia, mas sim desnortear, aparvalhar, atordoar a ingenuidade do espectador (LOBATO, 1922, p. 32).

A pintura de Anita Malfatti, intitulada A mulher de cabelos verdes, pode ter servido de inspiração à Cecília Meireles, porém, na incapacidade de se afirmar essa informação, é possível apenas ressaltar a curiosa aproximação entre essas duas manifestações artísticas, que apresentam personagens femininas ligadas por um traço peculiar tão incomum: os cabelos verdes.

Tal traço não apenas nos leva a sair de um plano "racional" e concreto, uma vez que, no caso da obra de Anita Malfatti a presença dos cabelos verdes pode indicar as inúmeras nuances que a luz reflete ao modo impressionista, mas também um jogo que pode demonstrar a indicação da faixa etária da mulher, que parece relativa, uma vez que a imagem mostrada representa uma idosa de cabelos brancos, mas que conserva nos olhos o sonho característico da mocidade. Nesse sentido, a cor verde pode indicar esse contraste formado pelos elementos contrários: velhice e juventude.

Nas poesias de Cecília Meireles esse caráter nórdico também se sobressai. Segundo Sampaio:

[...] sua poesia transfiguradora e sobrenatural acerca-se mais do cunho de qualquer poeta nórdico que da sensualidade tropical da também brasileira Adalgisa Neri, outra grande poetisa: esta ama cada forma, tudo que toca, tudo que acaricia; cada coisa lhe diz: "Adalgisa!", o que nunca aconteceria a Cecília Meireles, pois se uma acaricia e permanece (tropicalismo indolente e sensual), a outra reduz e ascende (atavismo europeu que Cecília constantemente relembra) (SAMPAIO, 1949, s/p).

Em "Desenho do sonho" de Cecília Meireles, os “cabelos verdes” também provocam múltiplas interpretações, fazendo com que a personagem não seja identificada quanto à idade, mas sim pelo estado de espírito, que apresenta a tranquilidade de quem sonha. Os cabelos, símbolo da feminilidade, crescem como plantas e formam ramagens densas.

Em A mulher de cabelos verdes, por sua vez, observa-se um plano de fundo fragmentado caracterizado por traços cubistas num jogo de matizes claros e escuros. Assim, os traços da face da mulher retratada também refletem traços angulosos que remetem à mesma vanguarda. 


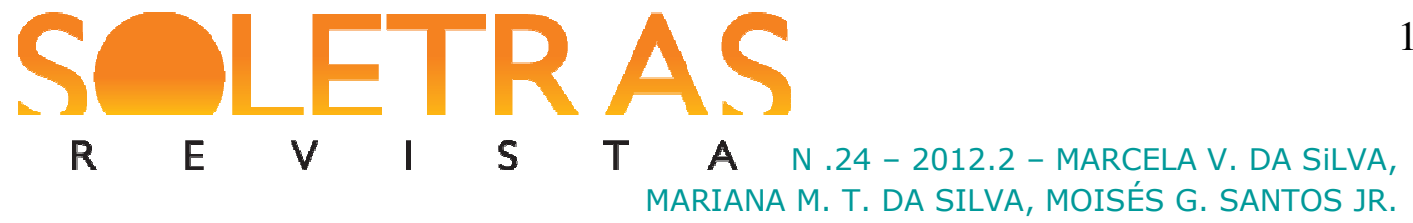

Os cabelos, vistos em diferentes ângulos adquirem cores diferentes, num jogo de iluminação. Todavia, o quadro é essencialmente expressionista, pois a deformação da imagem é clara e se dá pela ideia de ressaltar os sentimentos e o tom introspectivo da mulher representada. Somam-se a isso as cores vibrantes e os contornos bem marcados, em que os tons puros lembram elementos característicos da estética fauvista.

Nos anos 1915 e 1916 conviveria com elementos, acontecimentos e idéias das duas correntes polarizadoras da arte moderna norte-americana, justamente no período de maior euforia com as escolas européias. Conviveria com as duas influências dominantes entre os norte-americanos, fauvismo e cubismo - que dariam cor e forma às tendências e à formação da expressionista. (...) Anita se interessava mais pela estrutura da obra; as formas já eram muito marcadas. A cor, festa renovada, não é mais sua única preocupação... (BATISTA, 2006, p. 32-37).

O olhar da figura feminina é o ponto ápice de expressão dos mais recônditos e profundos sentimentos, sugerindo um momento de mergulho do eu que acaba por refletir a alma nos olhos.

Esse olhar ambíguo, que não fixa nada, que parece perdido em meio a lembranças e que se conserva sereno e enigmático (lembrando em demasia "Monalisa", de Leonardo Da Vinci), associa-se à loucura e ao mesmo tempo à tranquilidade. A mulher representada chama a atenção pela paz que transmite. O mesmo ocorre no poema "Desenho do sonho", cuja cadência nos sons dos versos, sua musicalidade e a própria descrição das "imagens" levam o leitor a um estado de paz espiritual e de serenidade, próprio da estética simbolista.

O simbolismo em "Desenho do sonho" encontra-se presente no jogo de sentidos observáveis na passagem "Surda é a transparência do mundo que ocupo" (MEIRELES, 1994, p. 1264-1265); a presença de musicalidade mediante a insistência de sons sibilantes em "Sigo dentro desse cristal ondulante, / Contida como o som dos sinos imóveis" (MEIRELES, 1994, p. 1264-1265); a temática do transcendental e do místico em "Surda é a transparência do mundo que ocupo, / onde vago, em vigilância do eterno, livre do efêmero visível e tranquila" (MEIRELES, 1994, p. 1264-1265) e a prevalência do verso livre e prosaico, conquista pioneira dos simbolistas.

Partindo da premissa de que toda a poética é envolta num clima onírico, em que se instaura o absurdo e o ilógico, Cecília Meireles desenvolve uma "linguagem psicológica", buscando em combinações inusitadas como em "Eu, mulher dormente, de olhos fechados, / estou vendo essas paredes fluidas que caminham comigo mesma”; “Ah! dos meus cabelos 


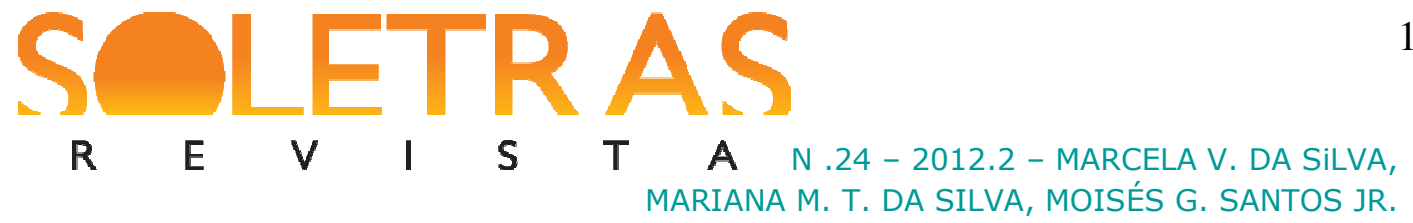

sobem agora ramos de rosas, alta coroa de retrato submerso" (MEIRELES, 1994, p. 12641265) e em expressões polivalentes, como "líquida noite", "sinos imóveis", “cristais ondulantes", "paredes fluidas", "luz de nenhum sol", recursos que potencializam a carga surrealista na edificação de um cenário mágico e fantástico.

Primordial também é evidenciar que o Expressionismo, trabalhando com os sentimentos aflorados e vibrantes, e sendo o precursor do Surrealismo na tentativa de pesquisas do espaço psicológico e interior, realiza-se nas seguintes expressões: "desenhando-me involuntária, / buscando-me exata" (MEIRELES, 1994, p. 1264-1265) e "frágil e melancólica" (MEIRELES, 1994, p. 1264-1265), pois a carga semântica destas passagens reflete um forte sentimento de busca de si mesmo, uma real essência que também é encontrada no quadro de Malfatti, pois através do olhar vago da figura feminina pressupõe-se a edificação de um universo próprio, anseio de uma identidade solitária, concretizada nas palavras de Meireles: “[...] livre do efêmero visível e tranquila, / e embora incomunicável, em solidão feliz" (MEIRELES, 1994, p. 1264-1265).

Há também que se destacar em ambas as produções um tema recorrente: a efemeridade da vida. Tanto a artista plástica quanto a poeta souberam trabalhá-lo de modo semelhante. Em Malfatti, a mulher idosa, sentada em uma cadeira com o olhar perdido evoca a espera da morte. Já em Meireles, o eu-lírico aproxima tudo do plano do sonho, a realidade dissipa-se, há uma fragilidade das coisas, cujo símbolo da rosa mostra de modo delicado a ideia de que a vida é curta e a qualquer momento se esvai, como em "Ah, dos meus verdes cabelos sobem agora ramos de rosas, alta coroa de retrato submerso" (MEIRELES, 1994, p. 1265). Essa presença da morte, porém não é sentida pelas personagens representadas como algo triste, inquietante. Elas esperam serenas por esse encontro, pois ele representa também mais uma tentativa de autoconhecimento, de autoaceitação.

Assim como o limiar entre a vida e a morte foi um dos momentos de revelação para Anita Malfatti aos treze anos, Cecília Meireles também captou essa temática por vivenciá-la de perto, uma vez que precisou enfrentá-la desde cedo com a morte de seus pais. Segundo Dal Farra (2006):

[...] é espantoso que Cecília afiançará, mais tarde, à posteridade, que esse sentimento que tão cedo a impregnou, a noção de "transitoriedade de tudo", pois que está impressa na sua vida desde logo ao nascer, tornou-se o fundamento mesmo da sua personalidade. E que, muito embora as mortes dos seus lhe tenham oprimido e maltratado, acarretando muita dor e outros tantos contratempos materiais, acabaram por lhe imprimir "uma tal 


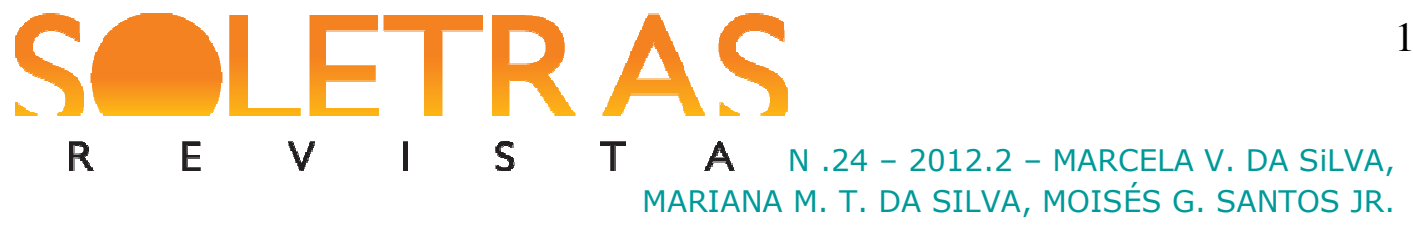

intimidade com a Morte", que fez com que ela conhecesse desde cedo e "docemente" - e é essa a palavra que ela usa! - as relações entre o Efêmero e o Eterno, aprendizagem que, geralmente para os outros, é muito penosa "e, por vezes, cheia de violência" (DAL FARRA, 2006, s/p).

Além da semelhança temática, Malfatti e Meireles aproximam-se na caracterização dada às personagens femininas. É possível apontar algumas zonas privilegiadas a partir das quais emerge a questão da mulher nessa obra. Em ambas, há a referência aos cabelos, símbolo da feminilidade. Em Malfatti, o contraste das cores e do semblante e olhar da mulher que contempla o nada; em Meireles, a presença de objetos especulares vistos em sonho, tais como o "espelho" e o "retrato" que ajudam a definir, tanto os limites entre real e irreal, quanto permitem criar uma expectativa de que o eu-lírico se reconheça.

Assim, percebe-se que há, na linguagem pictórica de Anita Malfatti, características que a aproximam das artes vanguardistas, procurando, sobretudo, chocar e transgredir os pressupostos artísticos tradicionais, mas também encerrando em sua estrutura elementos que figuram um eu oculto, fragmentado e envolto em misteriosas quimeras. É nesse sentido que mantém diálogo com a poesia de Cecília Meireles, tão voltada para a introspecção e o onírico.

\section{Considerações finais}

O eu-lírico, ao término do poema "Desenhos do sonho", declara: "E nem suspiro se as flores se desfolharem nesse planeta de silêncio" (MEIRELES, 1994, p. 1264-1265). Com este verso-síntese, Meireles rasga as cortinas que separam a realidade do mundo abstrato e, através dessa façanha, procura incansavelmente na poética seu $e u$ absoluto.

Do mesmo modo, Anita Malfatti usa o retrato para afirmar o caráter sensível da obra de arte, que não precisa buscar no real e concreto da vida seu modus faciendi. Suas obras, apesar de buscarem elementos das vanguardas europeias inovam pela mescla desses variados elementos.

Assim, em virtude da explanação realizada em torno do diálogo entre o quadro de Anita Malfatti e da poética de Cecília Meireles, depreende-se que as artistas conseguiram tratar de sentimentos particulares do indivíduo moderno e transpô-los numa ótica universal.

\section{Referências bibliográficas:}




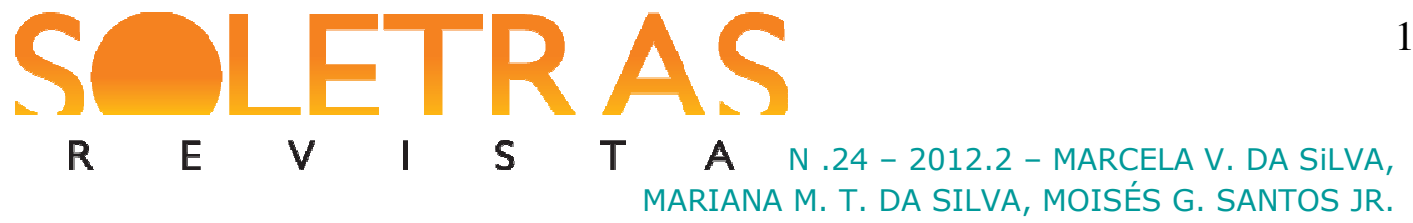

AMARAL, Aracy A. Artes plásticas na Semana de 22: subsídios para uma história da renovação das artes no Brasil. 4. ed. São Paulo: Perspectiva, 1979.

ANDRADE, Mário de. Anita Malfatti. In: Jornal de Debates, São Paulo, 1921.

ANDRADE, Oswald de. Piratininga Ano 374 da Deglutição do Bispo Sardinha. Revista de Antropofagia, Ano 1, n. 1, Maio de 1928.

BATISTA, Marta Rossetti (org.). In: Mário de Andrade. Cartas a Anita Malfatti. Rio de Janeiro: Forense Universitária, 1989.

A PINTORA DE 22: ANITA MALFATTI. Disponível em: $<$ http://quadroseretratos.wordpress.com/2012/06/11/a-pintora-de-22/>. Acesso em 21 de setembro de 2012.

AYALA, Walmir. Introdução. In: MEIRELES, Cecília. Poesia completa. Rio de Janeiro: Nova Aguilar, 1994.

BATISTA, Marta Rossetti et alii. Brasil: $1^{o}$ tempo modernista 1917/25: documentação. São Paulo: IEB, USP, 1972.

BATISTA, Marta Rossetti. Anita Malfatti no tempo e no espaço. São Paulo: EDUSP, 2006.

BOSI, Alfredo. História concisa da literatura brasileira. São Paulo: Cultrix, 2006.

CARDOSO, Renata Gomes. A crítica de arte no entorno de Anita Malfatti e seu reflexo na história da arte brasileira. Disponível em: <http://www.unicamp.br/chaa/rhaa/downloads/Revista\%209\%20-\%20artigo\%207.pdf>. Acesso em 20 de junho de 2012.

CHEVAlIER, J. GHEERBRANT, A. Dicionário de símbolos: mitos, sonhos, costumes, gestos, formas, figuras, cores, números. Rio de Janeiro: José Olympio, 2009.

COMPAGNON, Antoine. Os cinco paradoxos da modernidade. Belo Horizonte: UFMG, 1996.

CEIA, Carlos. Ut pictura poesis. In. E-Dicionário de termos literários. Disponível em: $<\mathrm{http}$ ///www.edtl.com.pt/index.php?option=com_mtree\&task=viewlink\&link_id=20\&Itemid= $>$. Acesso em 27 de setembro de 2012.

DAL FARRA, Maria Lúcia. Cecília Meireles: imagens femininas. Cadernos Pagu (ISSN 0104-8333), Cad. Pagu no.27 Campinas July/Dec. 2006. Disponível em: http://www.scielo.br/scielo.php?script=sci_arttext\&pid=S0104-83332006000200013. Acesso em 11 de dezembro de 2012.

ELIOT, Thomas Stearns. Tradição e talento individual. In: Ensaios. São Paulo: Art, 1989.

GONÇALVES, José Aguinaldo. Museu movente: o signo da arte em Marcel Proust. São Paulo: Editora UNESP, 2004. 


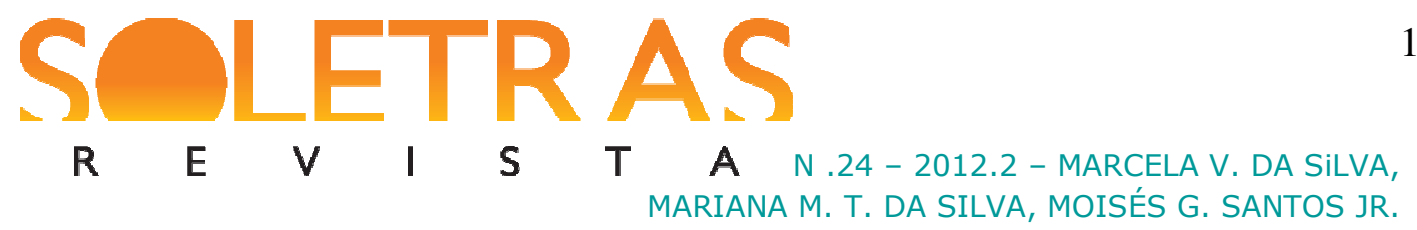

HELENA, Lúcia. Movimentos da vanguarda europeia. São Paulo: Editora Scipione, 1993.

HORÁCIO. Epistola ad Pisones. In: A poética clássica. São Paulo: Cultrix, 1995.

IONTA, Marilda Aparecida. As cores da amizade na escrita epistolar de Anita Malfatti, Oneyda Alvarenga, Henriqueta Lisboa e Mário de Andrade. 2004. 315p. Tese de doutoramento. Departamento de História. Instituto de Filosofia e Ciências Humanas - IFCH. Universidade Estadual de Campinas.

LOBATO, Monteiro. Paranoia ou mistificação? In: Ideias de Jeca Tatu. 3. ed. São Paulo: Monteiro Lobato \& Cia., 1922.

LOPES, Delvanir. Solombra: "sobre um passo de luz outro passo de sombra". $1^{o}$ CIELLI Colóquio Internacional de Estudos Linguísticos e Literários E $4^{\circ}$ CELLI Colóquio de Estudos Linguísticos e Literários. Universidade Estadual de Maringá - UEM Maringá-PR, 9, 10 e 11 de junho de 2010 - ANAIS - ISSN 2177-6350. Disponível em:< http://anais2010.cielli.com.br/downloads/668.pdf>. Acesso em 11 de dezembro de 2012.

MEIRELES, Cecília. Poesia completa. Rio de Janeiro: Nova Aguilar, 1994 (Volume único).

PEDROSO JÚNIOR, Neurivaldo Campos. Estudos interartes: uma introdução. Raído, Dourados, MS, v. 3, n. 5, p. 103-111, jan.-jun. 2009. Disponível em: <http://www.periodicos.ufgd.edu.br/index.php/Raido/article/view/161/224>. Acesso em $27 \mathrm{de}$ setembro de 2012.

SAMPAIO, Nuno de. O purismo lírico de Cecília Meireles. O Comércio do Porto. Porto, 16 de agosto de 1949.

TELES, Gilberto Mendonça. Vanguarda europeia e modernismo brasileiro. Petrópolis, RJ: Vozes, 2000.

\title{
European avant-gardes in aesthetic creation of Anita Malfatti and Cecília de Meireles: a study inbetween arts
}

\begin{abstract}
In modernity relations interart intensified because the modern movements are characterized by activities, programs and manifestos shared by artists from various fields. With the advent of Modernism and the avant-garde, poetic and pictorial experiences are renewed. This article therefore seeks to discuss the interference of the avant-garde movements of the early twentieth century in the process of Brazilian artistic composition. Such discussions will be based on the works of painter Anita Malfatti and poet Cecilia Meireles. Therefore, the corpus consists of the selected picture "A mulher de cabelos verdes" (19151916) and the poem "Desenhos do sonho" present in the work Sonhos, published in the anthology Complete Works (1994).
\end{abstract}




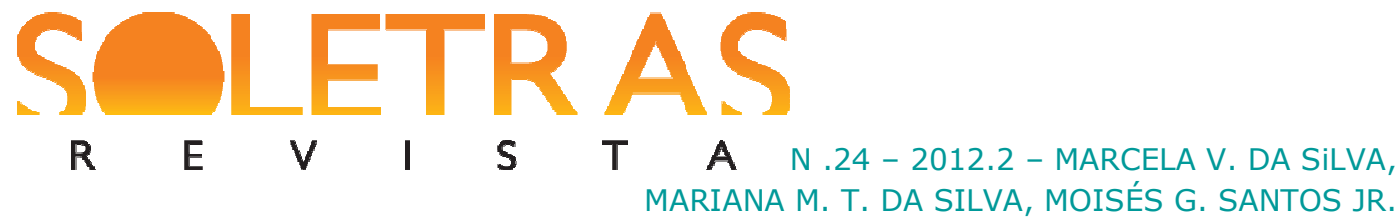

Key-words: Avant-gardes. Anita Malfatti. Cecília Meireles.

Recebido em: 17 de dezembro de 2012

Aprovado em: 03 de janeiro de 2013 